\title{
Partially substitution of wheat flour by coconut residues in bakery products and their physical and sensorial properties
}

\author{
${ }^{1, *}$ Eadmusik, S., ${ }^{1}$ Phungamngoen, C., ${ }^{2}$ Panphut, W. and ${ }^{2}$ Budsabun, T. \\ ${ }^{1}$ Department of Agro-industry Technology and Management, Faculty of Agro-industry, King Mongkut's \\ University of Technology North Bangkok, 25230 Prachinburi, Thailand \\ ${ }^{2}$ Industrial Microbiology Program, Faculty of Science and Technology, Suan Sunandra Rajabhat University, \\ 10300 Bangkok, Thailand
}

\author{
Article history: \\ Received: 25 February 2021 \\ Received in revised form: 2 \\ April 2021 \\ Accepted: 13 June 2021 \\ Available Online: 23 January \\ 2022
}

Keywords:

Agricultural waste,

Cocos nucifera Linn,

Donut,

Cookies,

Sensory

DOI:

https://doi.org/10.26656/fr.2017.6(1).140

\begin{abstract}
The food process generates certain amounts of agricultural wastes and by-products. These materials are considerably non-valuable and normally sold for livestock feed. Coconut residue is one of the by-products obtained from coconut milk extraction. Thus, this study was aimed to valorise coconut residue powder (CRP) by partial substitution of wheat flour in deep fried donut and butter cookies and to investigate how different CRP substitution levels affect the physical and sensorial qualities of these bakery products. CRP was prepared by drying coconut residues at $55^{\circ} \mathrm{C}$ for $9 \mathrm{hrs}$, size reducing with a blender at 24,000 rpm for $40 \mathrm{~s}$ and sieving through a 35-mesh sifter. Protein, ash, fat and carbohydrate contents of coconut flour were $3.82,0.72,39.83$ and $55.64 \%$ on dry basis, respectively. After the utilization of CRP by partial substitution wheat flour in deep fried donut $(5 \%, 10 \%$ and $15 \%)$ and butter cookies $(10 \%, 15 \%$ and $20 \%)$, it was found that CRP can substitute wheat flour in the donut and cookies productions by $10 \%$ and $15 \%$, respectively. Donuts with higher substitution levels had lower specific volume but higher $L^{*}, a^{*}, \Delta E^{*}$-values, hardness and chewiness. For butter cookies, an increase in CRP substitution level led to higher hardness but it did not significantly affect the fracturability and the $\Delta E^{*}$-value. An increase in CRP substitution level also reduced the overall-liking score. The overall-liking scores of fried donuts with 10\% CRP substitution level and butter cookies with 15\% CRP substitution level were 6.43 (slightly like) and 7.00 (moderately like), respectively. This study showed the value-adding of agricultural waste such as coconut residue by its application in food production.
\end{abstract}

\section{Introduction}

It has been reported that agro-food industries produce such an amount of agro-industrial residues and by-products (Gaonkar and Furtado, 2021) which cause not only a problem in the treatment and final disposal of waste in the world but also significant economic costs (Cotabarren et al., 2019). The accumulation of untreated agro-waste in the environment has led to pollution and health hazard (Gaonkar and Furtado, 2021). Recently, there is an increasing interest in utilizing and valueadding to the agro-industrial residues, creating new sources of wealth that provide a greater economic return to the industrial process (Cotabarren et al., 2019). From 2012-2016, novel products from fruit and vegetable waste accounted for about $20 \%$ of all products existing in the food supply chain (FAO, 2019).
The coconut tree (Cocos nucifera Linn.) is a crop distributed in over 200 countries. Associated with the large-scale production, and consequently, a high amount of not used agro-industrial residues are generated (Gomes et al., 2021). de Araújo Neto et al. (2016) informed that the coconut structure consists of approximately $85 \%$ of wastes that are not used by the agro-industrial chain for the generation of new products. Common products from coconut are coconut water, coconut oil and coconut milk. Coconut milk is made by the extraction of coconut endosperm with or without the addition of water. This extraction generates coconut fiber, a fiber-rich by-product from coconut milk extraction, so-called coconut residue or coconut milk cake. According to Raghavendra et al. (2004), the process of coconut milk extraction generates about $30 \%$ coconut residue. Unfortunately, this residue has not been 
much utilized. It is normally used as a low-cost animal feed or left rotting. Although the application of coconut residue in food production can save economic cost and value-add to coconut by-products, a few researchers have been studied the utilization of coconut residue in food production (Raghavendra et al., 2004). Recently, it is reported that coconut residue contains $4-25 \%$ protein depending on the extraction process (Rodsamran and Sothornvit, 2018) and can be used as food-grade dietary fiber (Zheng et al., 2021) in bakery products (Trinidad et al., 2006)

Bakery products such as donuts, deep fried or baked food, and cookie are consumed in large quantities on a daily basis (Martins et al., 2017). They are mainly made of wheat flour and water. Other different ingredients are added depending on each specific product resulting in unique sensorial characteristics (Purlis, 2010). Despite the fact that typical quality characteristics are related to each product, surface color together with texture and flavor are the main characteristics considering the preference of consumers (Abdullah, 2008). Substitutions of wheat flour by food industrial by-products, such as soybean cake, orange peel and celery spent residue, for bakery production have been previously studied (Behera et al., 2013; Stoll et al., 2015; Sowbhagya et al., 2011). It was reported that the use of food industrial byproducts generally decrease the global acceptability of bread, cookies and cake (Gómez and Martinez, 2018). However, no research studies on the substitution of wheat flour by coconut residue in bakery products. Therefore, this present study is aimed to investigate the effect of different substitution levels of wheat flour by coconut residue on the physical and sensorial properties of deep fried donuts and butter cookies.

\section{Materials and methods}

\subsection{Plant materials}

Coconut residues, a by-product of coconut milk extraction, were kindly provided by Theppadungporn Coconut Co., Ltd. (Nakhonpathom, Thailand).

\subsection{Preparation of coconut residues powder}

Coconut residues powder (CRP) was prepared by drying coconut residues, a by-product from coconut milk extraction, at $55^{\circ} \mathrm{C}$ for $9 \mathrm{hrs}$ (moisture content less than $5 \%$ ) and ground with a blender (Buono-17778P, Taiwan) at $24,000 \mathrm{rpm}$ for $40 \mathrm{~s}$ to a fine powder. It was then sieved through a 35-mesh sifter, vacuum-packed in aluminum foil packs and stored in $4^{\circ} \mathrm{C}$ until used. Proximate analysis of fresh coconut residues and CRP were determined following the AOAC method (AOAC, 2000).

\subsection{Preparation of bakery products}

\subsubsection{Deep-fried donut preparation}

The dough was prepared by twice sieving wheat flour (319.4 g), salt (1.34 g) and baking powder (2.68 g) together. Sugar $(145.61 \mathrm{~g})$, yeast $(9.39 \mathrm{~g})$, melted unsalted butter (35.56 g), egg (20.80 g), vanilla flavor $(4.70 \mathrm{~g})$ and water $(131.52 \mathrm{~g})$ were mixed together separately and allowed to sit for $30 \mathrm{~min}$. After $30 \mathrm{~min}$, it was added with a mixture of wheat flour, salt and baking powder and kneaded to form dough. The dough was allowed to proof for $1 \mathrm{hr}$, rolled to a thickness of about 1 $\mathrm{cm}$ and cut into a ring-shaped sample. The donut dough was then deep fried at $180^{\circ} \mathrm{C}$ for 3 mins $(1.5$ mins each side) using a fryer (Fritel FR-1265, Belgium). Fried donut with CRP was obtained from a substitution of wheat flour with CRP at the level of 5,10 and $15 \%$ by weight and prepared as described above. The formulation of donut with CRP is shown in Table 1.

\subsubsection{Butter cookies preparation}

Butter cookies were prepared by mixing salted butter (100 g), margarine (130 g), sugar (125 g), egg (55 g) and vanilla flavor $(3.3 \mathrm{~g})$ together using a hand mixer for 6 mins. It was gradually added and well homogenized with sieved wheat flour (300 g) and baking powder (2.6 g) for 2 mins. The cookies dough was filled into a pastry bag with conical tip, pressed with hand on a baking sheet and baked at $200^{\circ} \mathrm{C}$ for 12 mins. Butter cookies with CRP were obtained from partially replacement wheat flour with CRP at the level of 10,15 and $20 \%$ by weight and prepared as described above. The formulation of butter cookies with CRP is shown in Table 1.

\subsection{Determination of physical properties}

\subsubsection{Color determination}

Color parameters $\left(\mathrm{L}^{*}, a^{*}\right.$ and $\left.b^{*}\right)$ of samples were measured with a colorimeter (HunterLab colorFlex 4510, USA.) using illuminant $\mathrm{D}$ and $65^{\circ}$ standard observer. The colorimeter was calibrated using white and black standard reflective calibration plates. The total color difference $\left(\Delta E^{*}\right)$ was calculated as following equation:

$$
\Delta \mathrm{E}^{*}=\sqrt{\left(\mathrm{L}^{*} 0^{-}-\mathrm{L}^{*}\right)^{2}+\left(\mathrm{a}^{*} 0-\mathrm{a}^{*} 1\right)^{2}+\left(\mathrm{b}^{*} 0-\mathrm{b}^{*}\right)^{2}}
$$

Where $L^{*}, a^{*}{ }_{0}$ and $b^{*}=$ the color parameters of a sample without CRP (control) and $L{ }_{1}, a^{*}{ }_{1}$ and $b^{*}{ }_{1}=$ the color parameters of a sample with CRP

\subsubsection{Textural profile analysis}

Textural profile analysis (TPA) of samples was performed using a TA-XT plus texture analyser (Stable Micro System Ltd, Godalming, UK). The donut sample was measured by using a $36 \mathrm{~mm}$ diameter-cylindrical probe compressed to $60 \%$ of the original height with the 
Table 1. Formulations of donut and butter cookies with different levels of CRP

\begin{tabular}{lcccccccc}
\hline \multirow{2}{*}{ Ingredients (g) } & \multicolumn{9}{c}{ Donut } \\
\cline { 2 - 9 } & Control & $5 \%$ & $10 \%$ & $15 \%$ & Control & $10 \%$ & $15 \%$ & $20 \%$ \\
\hline Wheat flour & 319.4 & 303.43 & 287.46 & 271.49 & 300 & 270 & 255 & 240 \\
CRP & - & 15.97 & 31.94 & 47.91 & - & 30 & 45 & 60 \\
Salt & 1.34 & 1.34 & 1.34 & 1.34 & - & - & - & - \\
Baking powder & 2.7 & 2.7 & 2.7 & 2.7 & 2.6 & 2.6 & 2.6 & 2.6 \\
Sugar & 145.6 & 145.6 & 145.6 & 145.6 & 125 & 125 & 125 & 125 \\
Yeast & 9.4 & 9.4 & 9.4 & 9.4 & - & - & - & - \\
Butter & 35.56 & 35.56 & 35.56 & 35.56 & 100 & 100 & 100 & 100 \\
Egg & 20.8 & 20.8 & 20.8 & 20.8 & 55 & 55 & 55 & 55 \\
Vanilla flavor & 4.7 & 4.7 & 4.7 & 4.7 & 3.3 & 3.3 & 3.3 & 3.3 \\
Water & 132 & 132 & 132 & 132 & - & - & - & - \\
Margarine & - & - & - & - & 130 & 130 & 130 & 130 \\
\hline
\end{tabular}

${ }^{1}$ Unsalted butter for the donut formulation, Salted butter for the cookies formulation.

penetration speed of $1.7 \mathrm{~mm} / \mathrm{s}$ (Vélez-Ruiz and SosaMorales, 2003). The butter cookies sample was measured by using a $20 \mathrm{~mm}$ diameter-cylindrical probe compressed to $40 \%$ of the original height with the pretest and post-test speeds of 2.0 and $10 \mathrm{~mm} / \mathrm{s}$, respectively (das Chagas et. al., 2021). Hardness (g), springiness $(\mathrm{mm})$, cohesiveness $(\mathrm{g})$, chewiness $(\mathrm{g})$ and fracturability (g) were quantified from the TPA curve. Textural profile of donut measured include hardness, springiness, cohesiveness and chewiness while that of cookies include only hardness and fracturability.

\subsubsection{Specific volume}

The volume of donut samples was determined using the rapeseed displacement (AACC, 2000). The weight (g) of samples was measured using a 4-digit balance. The specific volume was calculated by dividing the volume by the weight as following equation:

$$
\text { Specific volume }\left(\frac{\mathrm{cm}^{3}}{\mathrm{~g}}\right)=\frac{\text { volume }\left(\mathrm{cm}^{3}\right)}{\text { weight }(\mathrm{g})}
$$

\subsubsection{Shape, size and spread ratio}

The shape and size of cookies were determined by a measurement of thickness $(\mathrm{cm})$ and width $(\mathrm{cm})$ using a caliper. The spread ratio was calculated as following equation (AACC, 2000).

$$
\text { Spreadratio }=\frac{\text { width }(\mathrm{cm})}{\text { thickness }(\mathrm{cm})}
$$

\subsection{Sensorial evaluation}

The sensorial evaluation was carried out by forty (40) untrained panelists. All samples were coded in 3digit numbers and presented in a randomized arrangement. Tests on color, smell, taste, texture and overall liking were conducted on a 9-point hedonic scale (1.00 to 1.89 - extremely dislike; 1.90 to 2.79 -very much dislike; 2.80 to 3.69 -moderately dislike; 3.70 to $4.59-$ slightly dislike; 4.60-5.49 - neither like nor dislike; 5.50 to 6.59 - slightly like; 6.60 to 7.69 - moderately like; 7.70 to 8.79 - very much like and 8.80 to $9.00-$ extremely like). A five-point rating just-about-right (JAR) was applied to examine the intensity of color, smell, taste (sweetness) and texture (hardness). It was a scale from 1-not enough to 5-too much and 3 neutral points.

\subsection{Statistical analysis}

Experiments were carried out in triplicate. The data were expressed as mean \pm standard deviation. The means of all parameters were examined using analysis of variance (One-way ANOVA). Duncan's New Multiple Range Test (DMRT) was used to determine the multiple comparisons of mean values at a level of $\mathrm{P}<0.05$. An SPSS statistical program version 16 was used to carry out the calculation.

\section{Results and discussion}

\subsection{Proximate composition of CRP}

As shown in Table 2, the moisture content was gigantically decreased after drying from $47.70 \%$ in fresh coconut residues to $3.82 \%$ in CRP. The results of fresh coconut residues are similar to a previous study by Mohd Nor et al. (2017) who reported $55.42 \%$ moisture, $1.69 \%$ protein, $17.26 \%$ fat, $0.54 \%$ ash and $25.73 \%$ carbohydrate contents of defatted coconut residues. The crude protein content of CRP was $3.67 \%$ wet basis or $3.82 \%$ dry basis. It was also similar to a study by de Araújo Neto et al. (2016) who reported that coconut power had a $4.9 \%$ protein dry basis. However, Ranghavendra et al. (2004) found $62 \%$ fat content in coconut residues. The difference in chemical compositions was associated with the various preparation methods in order to obtain coconut residues. 
Table 2. Chemical compositions of fresh coconut residues and CRP

\begin{tabular}{lccc}
\hline \multirow{2}{*}{ Composition } & $\begin{array}{c}\text { Fresh coconut } \\
\text { residue }\end{array}$ & \multicolumn{2}{c}{ CRP } \\
\cline { 2 - 4 }$(\%$ wet basis $)$ & $(\%$ wet & $(\%$ dry \\
\hline Moisture & 47.7 & 3.82 & - \\
Crude protein & 1.99 & 3.67 & 3.82 \\
Crude fat & 20.83 & 38.31 & 39.82 \\
Ash & 0.38 & 0.69 & 0.72 \\
Carbohydrate by & 29.1 & 53.51 & 55.69 \\
difference & & &
\end{tabular}

\subsection{Suitable substitution level for fried donut}

\subsubsection{Physical properties of fried donut}

Results showed that $L^{*}, a^{*}$-and $b^{*}$-values of CRP were $90.66,0.24$ and 5.50, respectively. The color of donut with different CRP levels are shown in Table 3. Lower $L^{*}$-value and higher $b^{*}$-value in donut might be a result of the browning reaction that occurred during the frying process. Purlis (2010) stated that the formation of colour in bakery products during baking is due to the Maillard reaction and caramelization. Abdul and Iqbal (2011) reported that coconut contains both reducing sugars (glucose and fructose) and non-reducing sugar (sucrose). Coconut kernel is a good source of protein as well. The presence of reducing sugar and protein causes the Maillard browning reaction (Fennema, 1996). An increase in CRP level tends to provide a donut with greater $\Delta E^{*}$. It also increased hardness, chewiness but decreased the cohesiveness of CRP donuts. An increase in substitution level did not affect springiness and specific volume of fried donuts. These findings were in accordance with the previous studies. Nouri et al. (2017) investigated the effects of carrot pomace powder on fried donuts and reported an increase in carrot pomace powder resulting in higher hardness, lower specific volume but non-significant effect on the springiness of fried donuts.
Although the present study found no significant difference in the specific volume of CRP donuts, it tends to be lower with an increase of CRP substitution level. The textural property of bakery products involves gluten, a protein found in wheat flour, which is formed by glutenin and gliadin. Gluten entraps carbon dioxide gas during dough leavening (Biesiekierski, 2017). Substitution of wheat flour by any insoluble fibre such as CRP or other agricultural powder dilutes gluten concentration and consequently results in a disruption of gluten matrix formation which led to higher hardness and lower specific volume (Nouri et al., 2017; das Chagas et al., 2021)

\subsubsection{Sensorial properties of fried donut}

Donut without CRP (control donut) had the highest liking score in all attributes (Figure 1). The liking scores of donuts with 5\% CRP substitution level were in the range of slightly like in all attributes. Besides the color liking score, the results of donut with $10 \%$ substitution level were statistically similar $(p>0.05)$ to those with $5 \%$ substitution level although its texture was in the range of neither like nor dislike. Donut with $15 \%$ substitution level had the lowest scores in taste, texture and overall liking. Overall liking score of control donut was 7.99 (very much like). That of donut with $5 \%, 10 \%$ and $15 \%$ substitution levels were 6.43 (slightly like), 6.40 (slightly like) and 5.57 (slightly like), respectively. Results from JAR showed that all donuts were just about right in color but too little in smell (data not shown). All donuts were too little in softness except that the control was just about right in softness. Too little sweetness was observed in the donut with $15 \%$ substitution level. The decrease in sensorial liking score of donuts with CRP agreed well with the result of Gómez and Martinez (2018) who indicated that the addition of fruit and vegetable byproducts generally lowered the global acceptability of

Table 3. Color, textural profile and specific volume of donut with different levels of CRP

\begin{tabular}{lcccc}
\hline \multirow{2}{*}{ Parameters } & \multicolumn{4}{c}{ Substitution level } \\
\cline { 2 - 5 } Color & Control & $5 \%$ & $10 \%$ & $15 \%$ \\
\hline$L^{*}$ & $57.75 \pm 0.10^{\mathrm{b}}$ & $55.22 \pm 0.50^{\mathrm{c}}$ & $53.84 \pm 0.13^{\mathrm{d}}$ & $60.39 \pm 0.15^{\mathrm{a}}$ \\
$a^{*}$ & $15.83 \pm 0.06^{\mathrm{b}}$ & $15.86 \pm 0.30^{\mathrm{b}}$ & $17.55 \pm 0.12^{\mathrm{a}}$ & $13.39 \pm 0.11^{\mathrm{c}}$ \\
$b^{*}$ & $41.14 \pm 1.10^{\mathrm{a}}$ & $40.18 \pm 0.03^{\mathrm{b}}$ & $39.44 \pm 0.51^{\mathrm{c}}$ & $39.87 \pm 0.46^{\mathrm{bc}}$ \\
$\Delta \mathrm{E}^{*}$ & $0^{\mathrm{a}}$ & $2.72 \pm 0.35^{\mathrm{b}}$ & $4.62 \pm 0.26^{\mathrm{d}}$ & $3.85 \pm 0.13^{\mathrm{c}}$ \\
\hline Textural profile & & & & \\
\hline Hardness $(\mathrm{g})$ & $5394 \pm 237^{\mathrm{d}}$ & $6383 \pm 118^{\mathrm{c}}$ & $8785 \pm 192^{\mathrm{b}}$ & $12805 \pm 661^{\mathrm{a}}$ \\
Springiness $(\mathrm{mm})$ & $0.73 \pm 0.03^{\mathrm{b}}$ & $0.76 \pm 0.01^{\mathrm{ab}}$ & $0.79 \pm 0.01^{\mathrm{a}}$ & $0.77 \pm 0.03^{\mathrm{ab}}$ \\
Cohesiveness $(\mathrm{g})$ & $0.77 \pm 0.03^{\mathrm{a}}$ & $0.68 \pm 0.01^{\mathrm{b}}$ & $0.65 \pm 0.01^{\mathrm{b}}$ & $0.52 \pm 0.01^{\mathrm{c}}$ \\
Chewiness $(\mathrm{mJ})$ & $3158 \pm 27^{\mathrm{c}}$ & $3150 \pm 47^{\mathrm{c}}$ & $4722 \pm 66^{\mathrm{b}}$ & $7719 \pm 67^{\mathrm{a}}$ \\
\hline Specific volume $\left(\mathrm{cm}^{3} / \mathrm{g}\right)^{\mathrm{ns}}$ & $3.24 \pm 0.71$ & $3.07 \pm 0.07$ & $2.89 \pm 0.24$ & $2.72 \pm 0.13$ \\
\hline
\end{tabular}

Values are presented as mean \pm SD. Values with different letters within the same row are significantly different $(p<0.05)$.

${ }^{n s}$ Not statistically significant different $(\mathrm{p} \geq 0.05)$ 
baked products such as bread, cookies and cakes.

Combining both physical and sensorial properties, the substitution level of $10 \%$ was selected although its sensorial property was not significantly different from the donut with 5\% substitution level. In order to the most utilization of CRP with the highest sensorial acceptability, the $10 \%$ substitution level was thus considered an optimal level for donut production.

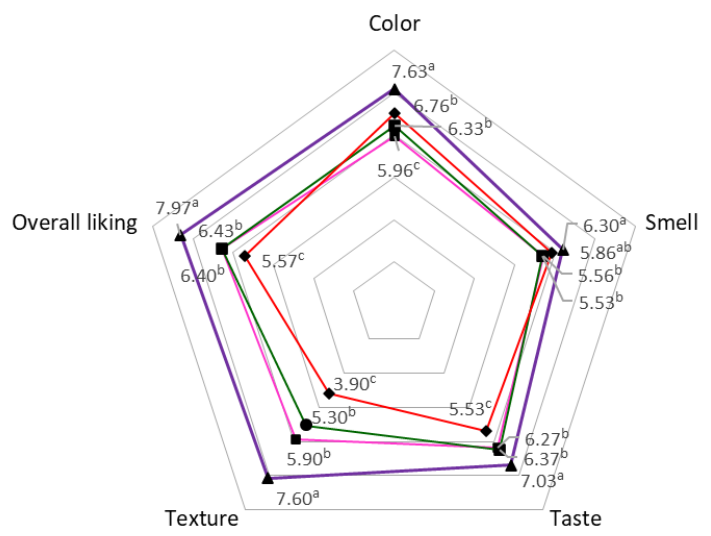

Figure 1. Sensorial liking score of donut with different substitution levels of CRP ( $\mathbf{\Delta}, 0 \%$ or control sample; $\mathbf{-}, 5 \%$; - $10 \%$ and $-15 \%$ ). Values within the same attribute with different notations are significantly different $(\mathrm{p}<0.05)$.

\subsection{Suitable substitution level for butter cookies}

\subsubsection{Physical properties of butter cookies}

Substitution with CRP in butter cookies resulted in a higher yellowness $\left(b^{*}\right.$-value) but had no significant effect on $a^{*}$-value (Table 4). An increase in substitution level did not affect color difference $\left(\Delta E^{*}\right)$ but resulted in higher hardness and fracturability of butter cookies. Spread ratio including width and thickness of cookies were not influenced by different substitution levels.

Increased $b^{*}$-value and hardness in butter cookies were similar to the results of fried donut. The previous studies found no significant difference in hardness of cookies produced from various substitution levels of wheat flour by camu-camu (Myrciaria dubia) coproduct powder das Chagas et al. (2021). However, the addition of camu-camu coproduct powder gave cookies with higher hardness compared to control cookies $(100 \%$ wheat flour cookies). Moreover, no significant influence of the substitution of wheat flour by $10 \%$ camu-camu coproduct powder on cookies' spread ratio was also reported, although reducing the substitution affected the spread ratio das Chagas et al. (2021). The spread ratio of cookies made from CRP, camu-camu coproduct powder and buriti endocarp flour were 3.80-4.14, 4.2-4.5 (das Chagas et al., 2021) and 3.19-5.24 (Becker et al., 2014), respectively. Changes in the physical property of cookies are related to the formation of the gluten network in cookies as described earlier in fried donut.

\subsubsection{Sensorial properties of butter cookies}

For all attributes, liking scores of cookies without CRP (control cookies), with $10 \%$ and $15 \%$ substitution levels were 6.67-7.61 (moderately like) while those of cookies with $20 \%$ substitution level were 5.58-6.49 (slightly like) (Figure 2). Butter cookies with $10 \%$ and $15 \%$ substitution levels had statistical similar liking scores in all attributes which ranged from 6.67 to 7.52 (moderately like). The highest overall liking score was obtained in control cookies which were not significantly different with cookies with a $10 \%$ substitution level, the lowest one was found in cookies with a $20 \%$ substitution level. However, it was not significantly different in cookies with $10 \%$ and $15 \%$ substitution levels, 7.18 (moderately like) and 7.00 (moderately like), respectively. JAR results showed butter cookies without CRP, with $10 \%$ and $15 \%$ substitution levels were just

Table 4. Color, textural profile, shape and size of butter cookies with different levels of CRP

\begin{tabular}{|c|c|c|c|c|}
\hline \multirow{2}{*}{ Parameters } & \multicolumn{4}{|c|}{ Substitution level } \\
\hline & Control & $10 \%$ & $15 \%$ & $20 \%$ \\
\hline \multicolumn{5}{|l|}{ Color } \\
\hline$L^{*}$ & $25.59 \pm 0.03^{b}$ & $27.53 \pm 1.1^{\mathrm{ab}}$ & $28.88 \pm 1.15^{\mathrm{a}}$ & $26.66 \pm 3.09^{\mathrm{ab}}$ \\
\hline$a^{* \mathrm{~ns}}$ & $7.88 \pm 0.05$ & $7.98 \pm 0.51$ & $8.07 \pm 0.49$ & $8.36 \pm 0.50$ \\
\hline$b^{*}$ & $20.24 \pm 0.07^{\mathrm{b}}$ & $21.22 \pm 0.82^{\mathrm{ab}}$ & $21.73 \pm 0.42^{\mathrm{a}}$ & $21.48 \pm 1.25^{\mathrm{a}}$ \\
\hline$\Delta E^{*}$ & $0^{\mathrm{a}}$ & $2.74 \pm 0.83^{\mathrm{b}}$ & $3.73 \pm 0.88^{b}$ & $2.78 \pm 0.61^{\mathrm{b}}$ \\
\hline \multicolumn{5}{|l|}{ Textural profile } \\
\hline Hardness (g) & $6750 \pm 836^{\mathrm{d}}$ & $8580 \pm 362^{c}$ & $18800 \pm 526^{\mathrm{b}}$ & $20500 \pm 1925^{a}$ \\
\hline Fracturability (g) & $4.29 \pm 0.53^{\mathrm{b}}$ & $4.52 \pm 0.75^{\mathrm{ab}}$ & $4.96 \pm 0.09^{\mathrm{a}}$ & $4.99 \pm 0.01^{\mathrm{a}}$ \\
\hline \multicolumn{5}{|l|}{ Shape and size } \\
\hline Width $(\mathrm{cm})^{\mathrm{ns}}$ & $4.38 \pm 0.15$ & $4.28 \pm 0.24$ & $4.20 \pm 0.10$ & $4.26 \pm 0.28$ \\
\hline Thickness $(\mathrm{cm})^{\mathrm{ns}}$ & $1.08 \pm 0.08$ & $1.14 \pm 0.15$ & $1.02 \pm 0.08$ & $1.06 \pm 0.09$ \\
\hline Spread ratio $^{\text {ns }}$ & $4.07 \pm 0.25$ & $3.80 \pm 0.53$ & $4.14 \pm 0.30$ & $4.04 \pm 0.46$ \\
\hline
\end{tabular}

Values are presented as mean \pm SD. Values with different letters within the same row are significantly different $(p<0.05)$.

${ }^{\mathrm{ns}}$ Not statistically significant different $(\mathrm{p} \geq 0.05)$ 
about right in all attributes but they were too much in cookies with a $20 \%$ substitution level (data not shown).

Concludingly, the physical and sensorial properties of cookies with $10 \%$ and $15 \%$ substitution levels were similar. For the same reason as in doughnut production, the most utilization of CRP, $15 \%$ substitution level was therefore selected as a suitable substitution level for butter cookies production.

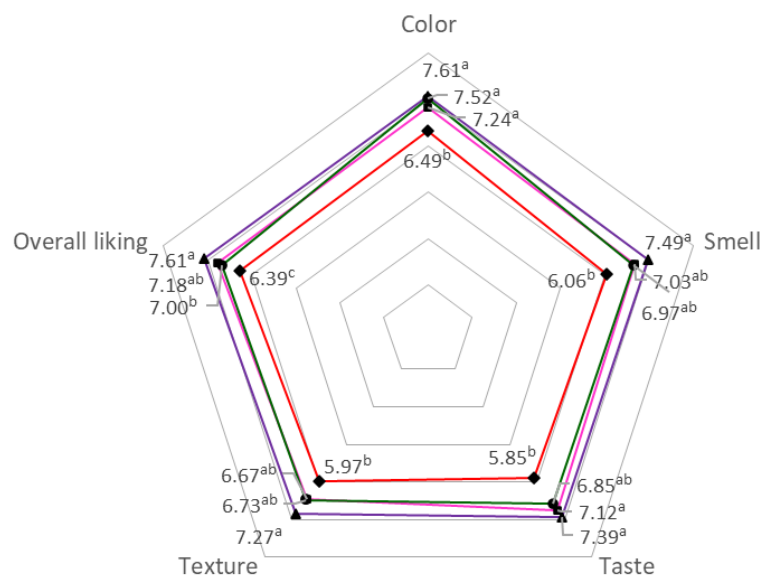

Figure 2. Sensorial liking score of butter cookies with different substitution levels of CRP $(\boldsymbol{\Lambda}, 0 \%$ or control sample; $-10 \% ; \bullet, 15 \%$ and $\bullet, 20 \%$ ). Values within the same attribute with different notations are significantly different $(\mathrm{p}<0.05)$.

\section{Conclusion}

The most suitable substitution levels of wheat flour by CRP in donut and butter cookies were $10 \%$ and $15 \%$, respectively. A higher substitution level tended to lower the products' properties, especially sensorial properties. Overall liking scores of the final products ranged in moderately like. This study demonstrates a potential utilization of CRP in donut and butter cookies productions which could be applied to other bakery products.

\section{Conflict of interest}

The authors declare no conflict of interest.

\section{Acknowledgments}

This research work was funded by Thailand Science Research and Innovation (TSRI) and Suan Sunandra Rajabhat University, Thailand (Project no. 0002407). The authors also appreciate the Faculty of Agro-industry, King Mongkut's University of Technology North Bangkok (KMUTNB) Prachinburi campus for the facilities and support.

\section{References}

AACC. (2000). Approved methods of the American
Association of cereal chemists. $10^{\text {th }}$ ed. St. Paul, Minnesota, USA: American Association of Cereal Chemists International.

Abdul, H.S. and Iqbal, M. (2011). Chemical composition of meat (kernel) and nut water of major coconut (Cocos nucifera L.) cultivars at coastal area of Pakistan. Pakistan Journal of Botany, 43(1), 357363.

Abdullah, M.Z. (2008). Quality evaluation of bakery products. In Sun, D.W. (Ed.), Computer vision technology for food quality evaluation, p. 481-522. Academic Press. https://doi.org/10.1016/B978012373642-0.50023-5

AOAC. (2000). Official method of analysis of AOAC International. Washington D.C., USA: Association of Official Analytical Chemists.

Becker, F.S., Damiani, C., de Melo, A.A.M., Borges, P.R.S. and de Barros Vilas Boas, E.V. (2014). Incorporation of buriti endocarp flour in gluten-free whole cookies as potential source of dietary fiber. Plant Foods for Human Nutrition, 69(4), 344-350. https://doi.org/10.1007/s11130-014-0440-y

Behera, S., Indumathi, K., Mahadevamma, S. and Sudha, M.L. (2013). Oil cakes-A by-product of agriculture industry as a fortificant in bakery products. International Journal of Food Sciences and Nutrition, $\quad 64(7), \quad 806-814 . \quad \mathrm{https}: / /$ doi.org/10.3109/09637486.2013.801405

Biesiekierski, J.R. (2017). What is gluten? Journal of Gastroenterology and Hepatology Foundation and John Wiley and Sons Australia, 32(Suppl. 1), 78-81. https://doi.org/10.1111/jgh.13703

Cotabarren, J., Rosso, A.M., Tellechea, M., GarcíaPardo, J., Rivera, J.L., Obregón, W.D. and Parisi, M.G. (2019). Adding value to the chia (Salvia hispanica L.) expeller: Production of bioactive peptides with antioxidant properties by enzymatic hydrolysis with papain. Food Chemistry, 274, 848856. https://doi.org/10.1016/j.foodchem.2018.09.061

das Chagas, E.G.L., Vanin, F.N., dos Santos Garcia, V.A., Yoshida, C.M.P. and de Carvalho, R.A. (2021). Enrichment of antioxidants compounds in cookies produced with camu-camu (Myrciaria dubia) coproducts powder. LWT-Food Science and Technology, 137, 110472. https://doi.org/10.1016/ j.lwt.2020.110472

de Araújo Neto, J.C., Fernandes, F.Y.B., Pimentel, J.C.M., Vasconcelos, V.R. and Azevedo, M.M.R. (2016). Nutritional value of whole coconut, coconut powder, and coconut fiber treated with sodium hydroxide for sheep. Cienciae Agrotecnologia, 40 (4), 475-483. https://doi.org/10.1590/1413- 


\section{5}

FAO. (2019). The State of Food and Agriculture 2019. Moving forward on food loss and waste reduction. Retrieved from FAO website: http://www.fao.org/ state-of-food-agriculture/2019/en

Fennema, O.R. (1996). Food Chemistry, $4^{\text {th }}$ ed. Marcel Dekker, New York: CRC Press.

Gaonkar, S.K. and Furtado, I.J. (2021). Valorization of low-cost agro-wastes residues for the maximum production of protease and lipase haloextremozymes by Haloferax lucentensis GUBF-2 MG076078. Process Biochemistry, 101, 72-88. https:// doi.org/10.1016/j.procbio.2020.10.019

Gomes, M.A., dos Santos Rocha, M.S.R., Barbosa, K.L., de Abreu, Í.B.S., de Oliveira Pimentel, W.R., De Farias Silva, C.E., Almeida, R.M.R.G., de Magalhães Cabral Albruquerque, E.C. and Vieira, R.C. (2021). Agricultural coconut cultivation wastes as feedstock for lignocellulosic ethanol production by Kluyveromyces marxianus. Waste and Biomass Valorization, 12, 4943-4951. https://doi.org/10.1007/ s12649-021-01345-w

Gómez, M. and Martinez, M.M. (2018). Fruit and vegetable by-products as novel ingredients to improve the nutritional quality of baked goods. Critical Reviews in Food Science and Nutrition, 58 (13), 2119-2135. https:// doi.org/10.1080/10408398.2017.1305946

Martins, Z.E., Pinho, O. and Ferreira, I.M.P.L.V.O. (2017). Food industry by-products used as functional ingredients of bakery products. Trends in Food Science and Technology, 67, 106-128. https:// doi.org/10.1016/j.tifs.2017.07.003

Mohd Nor, N.A.N., Abbasiliasi, S., Marikkar, M.N., Ariff, A., Amid, M., Lamasudin, D.U., Manap, M.Y.A. and Mustafa, S. (2017). Defatted coconut residue crude polysaccharides as potential prebiotics: Study of their effects on proliferation and acidifying activity of probiotics in vitro. Journal of Food Science and Technology, 54(1), 164-173. https:// doi.org/10.1007/s13197-016-2448-9

Nouri, M., Nasehi, B., Samavati, V. and Mehdizadeh, S.A. (2017). Optimizing the effects of Persian gum and carrot pomace powder for development of lowfat donut with high fibre content. Bioactive Carbohydrates and Dietary Fibre, 9, 39-45. https:// doi.org/10.1016/j.bcdf.2017.01.001

Purlis, E. (2010). Browning development in bakery products - A review. Journal of Food Engineering, 99(3), 239-249. https://doi.org/10.1016/ j.jfoodeng.2010.03.008

Raghavendra, S.N., Rastogi, N.K., Raghavarao,
K.S.M.S. and Tharanathan, R.N. (2004). Dietary fiber from coconut residue: Effects of different treatments and particle size on the hydration properties. European Food Research and Technology, 218(6), 563-567. https:// doi.org/10.1007/s00217-004-0889-2

Rodsamran, P. and Sothornvit, R. (2018). Physicochemical and functional properties of protein concentrate from by-product of coconut processing. Food Chemistry, 241, 364-371. https:// doi.org/10.1016/j.foodchem.2017.08.116

Sowbhagya, H.B., Mahadevamma, S., Indrani, D. and Srinivas, P. (2011). Physicochemical and microstructural characteristics of celery seed spent residue and influence of its addition on the quality of biscuits. Journal of Texture Studies, 42(5), 369-376. https://doi.org/10.1111/j.1745-4603.2011.00294.x

Stoll, L., Flôres, S.H. and Silveira Thys, R.C. (2015). Citrus peel fiber and its application as a fat substitute in loaf brad. Ciencia Rural, 45(3), 567-573. https:// doi.org/10.1590/0103-8478cr20131503

Trinidad, T.P., Mallillin, A.C., Valdez, D.H., Loyola, A.S., Askali-Mercado, F.C., Castillo, J.C., Encabo, R.R., Masa, D.B., Maglaya, A.S. and Chua, M.T. (2006). Dietary fiber from coconut flour: A functional food. Innovative Food Science and Emerging Technologies, 7(4), 309-317. https:// doi.org/10.1016/j.ifset.2004.04.003

Vélez-Ruiz, J.F. and Sosa-Morales, M.E. (2003). Evaluation of physical properties of dough of donuts during deep-fat frying at different temperatures. International Journal of Food Properties, 6(2), 341353. https://doi.org/10.1081/JFP-120017813

Zheng, Y., Tian, H., Li, Y., Wang, X. and Shi, P. (2021). Effects of carboxymethylation, hydroxypropylation and dual enzyme hydrolysis combination with heating on physicochemical and functional properties and antioxidant activity of coconut cake dietary fibre. Food Chemistry, 336, 127688. https:// doi.org/10.1016/j.foodchem.2020.127688 